\title{
Rational Design of Copper(II)-Uracil Nanoprocessed Coordination Polymers to Improve Their Cytotoxic Activity in Biological Media
}

\author{
Verónica G. Vegas, Ana Latorre, María Luisa Marcos, Carlos J. Gómez-García, Óscar Castillo, \\ Félix Zamora, Jacobo Gómez, José Martínez-Costas, Miguel Vázquez López, Álvaro Somoza,* \\ and Pilar Amo-Ochoa*
}

Cite This: ACS Appl. Mater. Interfaces 2021, 13, 36948-36957

Read Online

ABSTRACT: This work is focused on the rational structural design of two isostructural $\mathrm{Cu}(\mathrm{II})$ nano-coordination polymers (NCPs) with uracil-1-acetic acid (UAcOH) (CP1n) and 5fluorouracil-1-acetic acid (CP2n). Suitable single crystals for X-ray diffraction studies of $\mathrm{CP1}$ and $\mathrm{CP2}$ were prepared under hydrothermal conditions, enabling their structural determination as $1 \mathrm{D}-\mathrm{CP}$ ladder-like polymeric structures. The control of the synthetic parameters allows their processability into water colloids based on nanoplates (CP1n and CP2n). These NCPs are stable in water at physiological $\mathrm{pHs}$ for long periods. However, interestingly, CP1n is chemically altered in culture media. These transformations provoke the partial release of its building blocks and

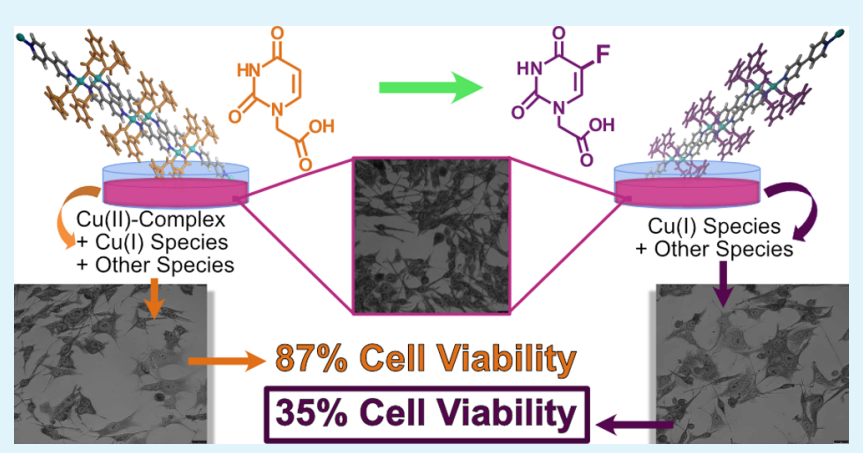
the formation of new species, such as $\left[\mathrm{Cu}(\mathrm{UAcO})_{2}\left(\mathrm{H}_{2} \mathrm{O}\right)_{4}\right] \cdot 2 \mathrm{H}_{2} \mathrm{O}(\mathrm{Cu}(\mathrm{II})$-complex $)$, and species corresponding to the partial reduction of the $\mathrm{Cu}(\mathrm{II})$ centers. The cytotoxic studies of $\mathrm{CP1n}$ versus human pancreatic adenocarcinoma and human uveal melanoma cells show that CP1n produces a decrease in the cell viability, while their $\mathrm{UAcOH}$ and $\mathbf{C u}(\mathrm{II})$-complex are not cytotoxic under similar conditions. The copper reduction species detected in the hydrolysis of CP1n are closely related to the formation of the reactive oxygen species (ROS) detected in the cytotoxic studies. These results prompted us to prepare CP2n that was designed to improve the cytotoxicity by the substitution of $\mathrm{UAcO}$ by 5-FUAcO, taking into account the anticancer activity of the 5-fluorouracil moiety. The new CP2n has a similar behavior to CP1n both in water and in biological media. However, its subtle structural differences are vital in improving its cytotoxic activity. Indeed, the release during the hydrolysis of species containing the 5fluorouracil moiety provokes a remarkable increase in cellular toxicity and a significant increase in ROS species formation.

KEYWORDS: coordination polymers, nano-coordination polymers, uracil, 5-fluorouracil, biological media, cytotoxicity

\section{INTRODUCTION}

Coordination polymers (CPs) are based on the organized assembly of metal entities with organic and inorganic ligands giving rise to one-, two-, or three-dimensional architectures. ${ }^{1-3}$ The large variety of the constituents allows the production of a huge structural variety, with almost a la carte physico-chemical properties, ${ }^{4,5}$ thanks to the combination of metal centers and ligands. ${ }^{6-9}$ A relatively common feature of most of the CPs is that they are quite insoluble in the reaction media, offering the possibility to form nanostructures in a one-pot bottom-up process ${ }^{8,10,11}$ upon adjustment of the experimental conditions (i.e., temperature, concentration, and/or solvents). ${ }^{12}$ The structural tunability of those nanostructures would enable the synthesis of nano-coordination polymers (NCPs) with different chemical and physical properties. ${ }^{13,14}$ Their nanometric size and an appropriate structural design enable NCPs to be useful as nanocarriers in biological processes. ${ }^{15}$

Besides, their coordination bonds are relatively labile. They can undergo exchange reactions with other ligands present in the medium as well as partial or complete solvolysis (hydrolysis). ${ }^{16}$

Understanding these chemical transformations can be crucial to take advantage of the use of CPs as pharmaceutical precursors. Indeed, it has been reported that the chemical response of some CPs enables them to be used to deliver molecules of biological interest, ${ }^{17}$ or even their chemical transformation and reorganization can in situ produce interesting new drugs. ${ }^{13,14,18-21}$

On the other hand, copper(II) ions can promote some selective cell toxicity, allowing the manufacture of coordination

Received: June 21, 2021

Accepted: July 13, 2021

Published: August 2, 2021 
complexes that can also be used as anticancer or antibacterial agents. ${ }^{17,21}$ The reports related to this topic are diverse, including those dealing with copper(II) coordination complexes with different cytotoxicity potentials, from non-toxic to highly toxic. ${ }^{22-25}$ However, these studies clearly show that the cytotoxicity of copper(II) complexes mainly depends on the type of ligands bound to the metal center and not in the presence of the copper(II) ion. ${ }^{26}$ It also seems that the cytotoxic activity and their interaction with the DNA are usually more significant in coordination complexes than in the precursor copper salts (i.e., hexa-aqua copper(II) complex). ${ }^{27,28}$ Previous studies have stressed that the mechanisms involved in the copper(II) cytotoxicity are not easy to unravel and the results depend on many experimental factors such as $\mathrm{pH}$, size, and biological media in addition to the solubility of the $\mathrm{Cu}(\mathrm{II})$ complexes. $^{29}$

It has to be noted that only a few studies are focused on the analysis of CPs in biological media. The results are beginning to show some indications about their possible behaviors and their relationship with their cytotoxic activity. ${ }^{15,30,31}$ In this regard, a recent study has shown that the cytotoxic activity of 16 different nano-MOFs primarily depends on their solubility in biological media and on the amount of metal ion [ $\mathrm{Zr}(\mathrm{IV})$, $\mathrm{Fe}(\mathrm{III}), \mathrm{Zn}(\mathrm{II}), \mathrm{Mn}(\mathrm{II}), \mathrm{Co}(\mathrm{II}), \mathrm{Ni}(\mathrm{II}), \mathrm{Cu}(\mathrm{II})$, and $\mathrm{Mg}(\mathrm{II})$ ] released. The most toxic are those that present a more significant amount of metal ion release. ${ }^{30}$ A disadvantage of the nano-MOFs studied from the biological point of view is that they are generally obtained or dispersed in organic solvents, therefore limiting the studies in biological conditions. ${ }^{30,32,33}$ They also reported that the nano-MOFs could undergo structural rearrangements and chemical reactions, producing new inorganic species in biological media. ${ }^{30}$

Therefore, the synthesis of new NCPs based on copper(II) with selected biological ligands such as uracil derivatives such as 5-fluorouracil (5-FU), one of the most effective antineoplastic agents, or related derivatives, could produce new materials with synergistic effects and interesting therapeutic properties. Moreover, its study in biological media is an exciting challenge from the pharmacological point of view.

Since previous studies still show a significant number of doubts and controversies, in this work, we try to deepen the design of new CPs considering their behavior in biological media. This work attempts to serve as a proof of concept in using NCPs as active drugs.

This study shows the one-step synthesis under hydrothermal conditions and the characterization of a new 1D-copper(II)uracil-1-acetate $\mathrm{CP}$. The $\mathrm{CP}$ has been nanoprocessed via bottom-up due to its high insolubility in water at room temperature. The obtained colloidal suspension of nanoplates becomes hydrolyzed in physiological serums, releasing some of its constituents into the environment and promoting a cytotoxic response. Based on this behavior, a modification was performed by synthesizing a new isostructural $\mathrm{Cu}$ (II) $\mathrm{CP}$ where 5-fluorouracil-1-acetate replaces uracil-1-acetate (Scheme 1). The new NCP is also hydrolyzed in the biological media, leading to a chemical reorganization of the $\mathrm{CP}$ and a partial release of the ligands. Furthermore, their in-vitro cytotoxicity in melanoma and pancreatic cancer cells has been studied, compared, and related with their chemical behavior and the selected building blocks. Indeed, the above-mentioned hydrolysis taking place in the biological media agrees with the higher cytotoxicity, and the greater generation of reactive
Scheme 1. Synthesis of $\left[\mathrm{Cu}_{2}(\mathrm{UAcO})_{4}\left(4,4^{\prime} \text {-bipy }\right)_{2}\right]_{n} \cdot 3 \mathrm{H}_{2} \mathrm{O}$

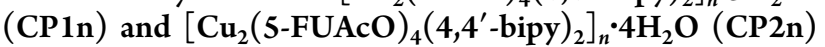
as a Water Colloid

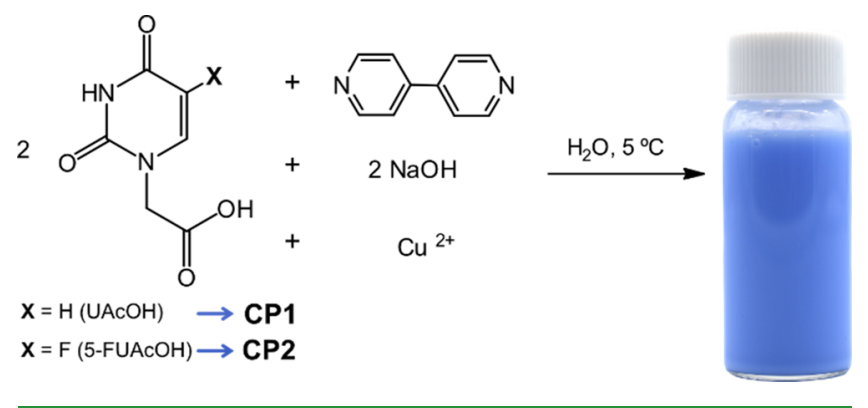

oxygen species (ROS) is observed when 5-fluorouracil-1-acetic acid (5-FUAcOH) is selected as the ligand.

\section{RESULTS AND DISCUSSION}

Synthesis and Structure. Good-quality single crystals of CP1 and CP2 were prepared under hydrothermal conditions ( $120{ }^{\circ} \mathrm{C}$ for 3 and 2 days of reaction time, respectively), enabling their structural determination.

CP1 consists of a 1D-CP ladder-like polymeric structure with the formula $\left[\mathrm{Cu}_{2}(\mathrm{UAcO})_{4}\left(4,4^{\prime} \text {-bipy }\right)_{2}\right]_{n} \cdot 3 \mathrm{H}_{2} \mathrm{O}$ (Figure $1)$. The copper(II) metal centers are bridged by double $\mu$ $\mathrm{UAcOH}-\kappa O: \kappa O \quad[3.4179(13) \AA]$ and $\mu-4,4^{\prime}$-bipy- $\kappa N: \kappa N^{\prime}$ $[11.1216(17) \AA]$ ligands to define the side rail and the rung of the ladder chain, respectively.

The copper(II) metal centers are bridged simultaneously by $\mu-4,4^{\prime \prime}$-bipy- $\kappa N: \kappa N^{\prime \prime}[11.1216(17) \AA]$ and double $\mu$-UAcOH$\kappa O: \kappa O[3.4179(13) \AA]$ ligands in such a way that they define what it would be the side rail and rung of a ladder like chain, respectively. The coordination geometry around the metal center includes the terminally coordinated uracil-1-acetate and the bridging 4,4'-bipy ligands to adopt an elongated $\mathrm{N}_{2} \mathrm{O}_{3}$ square pyramidal geometry. The basal plane is occupied by two trans arranged nitrogen atoms coming from the 4,4'-bipy ligands, an oxygen atom belonging to the carboxylate group of the terminally coordinated UAcO ligand, and a bridging UAcO ligand. The apical position is occupied by an oxygen atom from the UAcO bridging ligand and shows a significantly longer $\mathrm{Cu}-\mathrm{O}$ distance. The acetate ligand acquires an asymmetric $\mu$ oxo coordination mode where the same oxygen atom is located in the basal plane of a metal center $[1.961(6) \AA]$ and in the apical position of another copper(II) ion [2.403(6) $\AA]$. The existence of a double acetate bridge connecting the copper(II) centers (the rung of the ladder chain) gives rise to a $\mathrm{Cu}_{2} \mathrm{O}_{2}$ planar square with $\mathrm{Cu}-\mathrm{O}-\mathrm{Cu}$ and $\mathrm{O}-\mathrm{Cu}-\mathrm{O}$ angles of $99.7(2)$ and $80.3(2)^{\circ}$, respectively. The two coordinated carboxylate groups (from uracil-1-acetate ligands) are nearly coplanar to the $\mathrm{Cu}_{2} \mathrm{O}_{2}$ core $\left(3.23\right.$ and $1.59^{\circ}$, respectively). The $4,4^{\prime}$-bipy ligands are perpendicularly arranged with respect to this core $\left(89.55^{\circ}\right)$. Unsurprisingly, the uracil substituent is almost perpendicular to the same dinuclear core $\left(85.16^{\circ}\right)$ and nearly parallel to the $4,4^{\prime}$-bipy ligand $\left(8.14^{\circ}\right)$.

The uracil-1-acetate ligands coordinate the metal center using only one of their carboxylate oxygen atoms, leaving the rest of uracil available to stabilize the overall structure by means of supramolecular interactions. Nevertheless, in spite of the expected $\pi$-stacking interactions or direct complementary hydrogen bonding between the nucleobases, they interact favorably with the crystallization water molecules, and only $\mathrm{C}-$ 
(a)

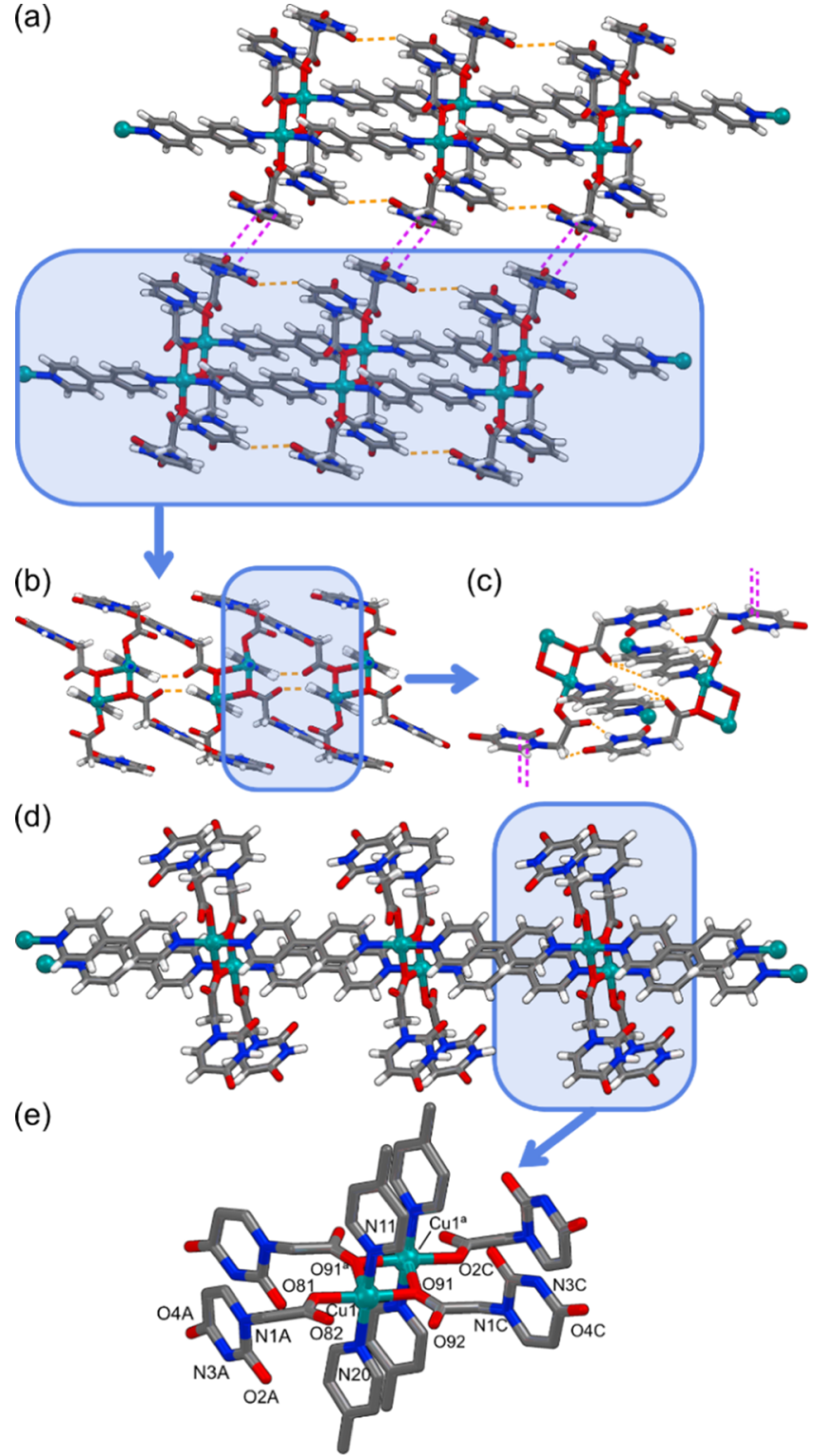

Figure 1. (a) Projection of the crystal packing of CP1 along the crystallographic $b$ axis, emphasizing the presence of supramolecular sheets held together by $\pi-\pi$ stacking interactions. $(b, c)$ Assembly of the polymeric $1 \mathrm{D}$ chains through hydrogen-bonding interactions. (d,e) Ladder-like CP and magnification of the metal coordination surrounding the labeling scheme. Orange single dashed lines indicate hydrogen-bonding interactions and purple double dashed lines the $\pi-\pi$ stacking interactions. The disorder of the uracil residue has been omitted for clarity.

$\mathrm{H}$... O hydrogen bond interactions are observed between the nucleobases. The latter interactions provide supramolecular sheets that propagate in the (001) plane. One of the crystallization water molecules establishes an $\mathrm{O} \cdots \mathrm{H}-\mathrm{Ow}-$ $\mathrm{H} \cdots \mathrm{O}$ double hydrogen bond with the two non-coordinated oxygen atoms of the two carboxylate groups coordinated to the metal center that strengthens their monodentate coordination mode. The remaining two crystallographically independent water molecules show additional $\mathrm{Ow}-\mathrm{H} \cdots \mathrm{Ow}, \mathrm{Ow}-\mathrm{H} \cdots \mathrm{O}$, and $\mathrm{N} 3-\mathrm{H} \cdots \mathrm{O}$ hydrogen bonds that give the final overall cohesiveness to the crystal structure.

The presence of two coordinated uracil-1-acetate ligands implies a greater capability to establish $\pi-\pi$ stacking interactions and hydrogen bonds in the supramolecular network. In fact, every ladder-like polymeric chain interacts with four surrounding chains, two of them employing hydrogen-bonding interactions and the other two through $\pi-\pi$ stacking interactions involving the uracil residues. The hydrogen-bonding interaction can hold together the polymeric chains in 2D supramolecular chains. Most of these hydrogenbonding interactions involve the non-coordinated oxygen atoms of the carboxylate groups as the acceptor and the uracil residue $\mathrm{N} 3-\mathrm{H}$ and bipyridine $\mathrm{C}-\mathrm{H}$ groups, but a direct $\mathrm{C}-$ $\mathrm{H} \cdots \mathrm{O}$ interaction is also found between the uracil residues belonging to adjacent chains. The $\pi-\pi$ stacking interactions between the terminal UAcO uracil residues held together the supramolecular sheets to generate the final 3D supramolecular architecture. On the other hand, the relatively irregular shape of the chains implies the presence of isolated voids within the crystal structure that comprise $19.3 \%$ of the total volume. However, as far as the direct supramolecular interactions between the polymeric chains saturate almost all the hydrogen bond donor and acceptor positions, the water molecules located in these voids are only loosely attached to the polymeric entities to provide a well-defined hydrogen-bonding scheme. The disorder of these water molecules is so high that their contribution was removed using the squeeze procedure as implemented in PLATON. ${ }^{34}$

CP2, obtained using the same synthetic route but replacing uracil-1-acetate with the 5-fluorouracil-1-acetate, presents a very similar $1 \mathrm{D}$ ladder-like metal-organic molecular structure (Figure 2). Again, the $\mu-4,4^{\prime}$-bipy- $\kappa N: \kappa N^{\prime}$ [11.1216(17) $\left.\AA\right]$

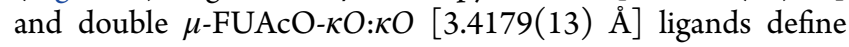
the side rail and the rung of the ladder chain, respectively, and the metal coordination sphere includes a terminally coordinated 5-fluorouracil-1-acetate- $\kappa O$ ligand to give an elongated $\mathrm{N}_{2} \mathrm{O}_{3}$ square pyramidal coordination geometry. The apical position showing a significantly longer coordination bond distance $(2.40 v s$ 1.94-2.01 $\AA$ ) is occupied by the oxygen atom of the bridging 5-fluorouracil-1-acetate ligand. The $\mathrm{Cu}_{2} \mathrm{O}_{2}$ planar square that defines the rung of the ladder presents $\mathrm{Cu}-\mathrm{O}-\mathrm{Cu}$ and $\mathrm{O}-\mathrm{Cu}-\mathrm{O}$ angles of $101.32(14)$ and $78.64(14)^{\circ}$, respectively. The $4,4^{\prime}$-bpy ligands are perpendicular to this core $\left(88.90^{\circ}\right)$, and the uracil residues are almost perpendicularly organized concerning the same dimeric core $\left(88.90\right.$ and $\left.89.15^{\circ}\right)$ and practically parallel with respect to the 4,4'-bipy ligand $\left(1.32\right.$ and $\left.9.37^{\circ}\right)$.

As it can be seen, the molecular features of CP1 and CP2 are almost identical. Still, the 5-fluorouracil residues, not involved in the coordination with the metal center, adopt slightly different supramolecular interactions connecting the ladder-like chains. In fact, fluorouracil residues are more efficient in establishing the expected complementary hydrogen bonds between the terminally coordinated 5-fluorouracil-

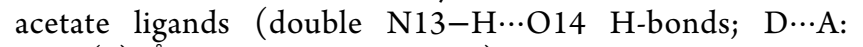
$2.867(7) \AA$ and $\left.\mathrm{D}-\mathrm{H} \cdots \mathrm{A}: 168.4^{\circ}\right)$, connecting each ladderlike chain with two adjacent ones. Simultaneously, the bridging 5-fluorouracil-acetate ligands reinforce this supramolecular interaction by establishing $\pi-\pi$ interactions $\left(9.3^{\circ}\right.$ between the planar rings and closest distances: $3.12-3.35 \AA$ ) between their 5-FU residue and the same residue belonging to the bridging 5-fluorouracil-acetate ligand of the adjacent chain, which is, as previously stated, also involved in the complementary $\mathrm{H}$-bond interaction. The simultaneous presence of both supramolecular interactions (H-bonding and $\pi-\pi$ interactions; Figure $2 \mathrm{~b}$ ) provides a strong synthon connecting 
(a)

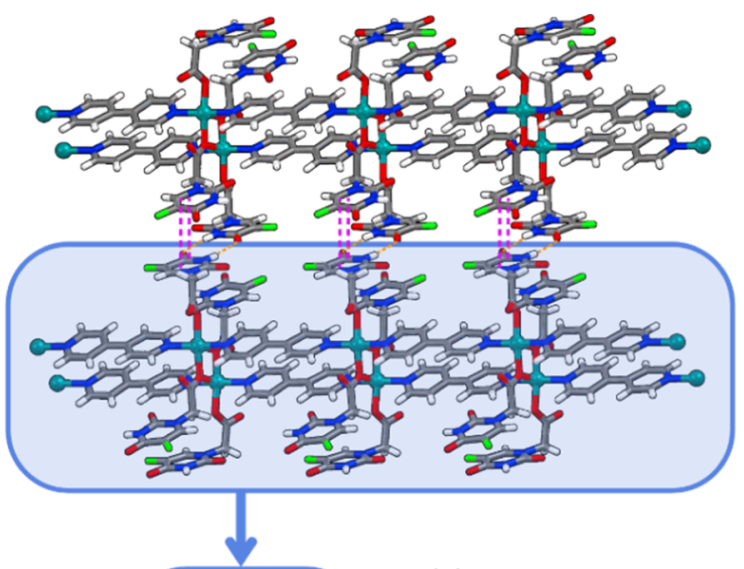

(b)

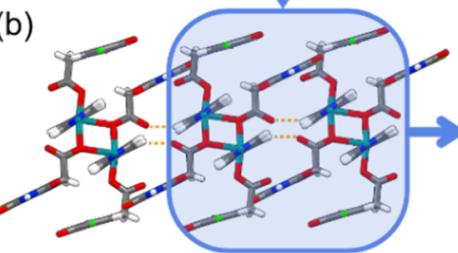

(c)

(d)

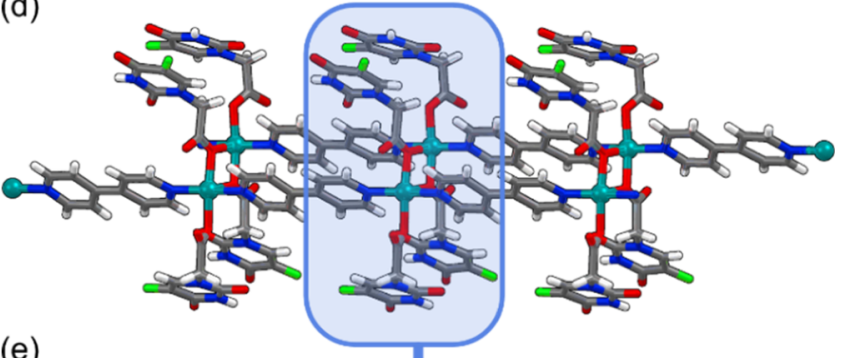

(e)

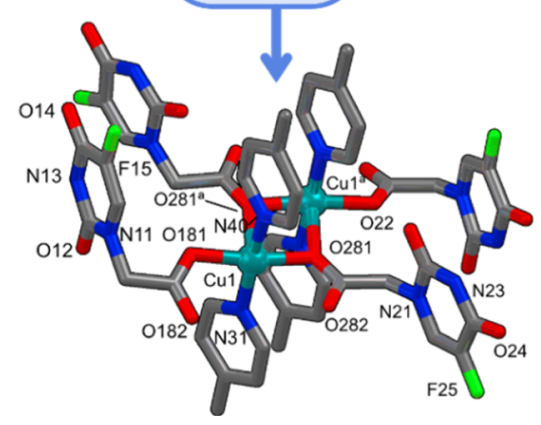

The one-pot reaction was carried out at $5{ }^{\circ} \mathrm{C}$ with uracil-1acetic acid ( $\mathrm{UAcOH})$ or 5-FUAcOH, $\mathrm{NaOH}, 4,4^{\prime}$-bipy, and $\mathrm{Cu}\left(\mathrm{NO}_{3}\right)_{2} \cdot 3 \mathrm{H}_{2} \mathrm{O}$ (Scheme 1), giving rise to the formation of blue-purple water colloids of CP1n and CP2n. Powder X-ray diffraction (PXRD) of CP1n and CP2n corroborate that they retain the same crystal structure of the bulk preparations (Figures S2 and S4). The morphological characterization, carried out by FESEM and AFM, confirms that CP1n consists of well-defined nanoplates $150 \pm 75 \mathrm{~nm}$ wide and $320 \pm 140$ $\mathrm{nm}$ long with thicknesses between 20 and $40 \mathrm{~nm}$ (Figures 3a,b and S7), while CP2n shows irregular nanoplate structures of about $284 \pm 70 \mathrm{~nm}$ wide and $345 \pm 90 \mathrm{~nm}$ long and heights of around $40-60 \mathrm{~nm}$ (Figures $3 \mathrm{c}, \mathrm{d}$ and S7).
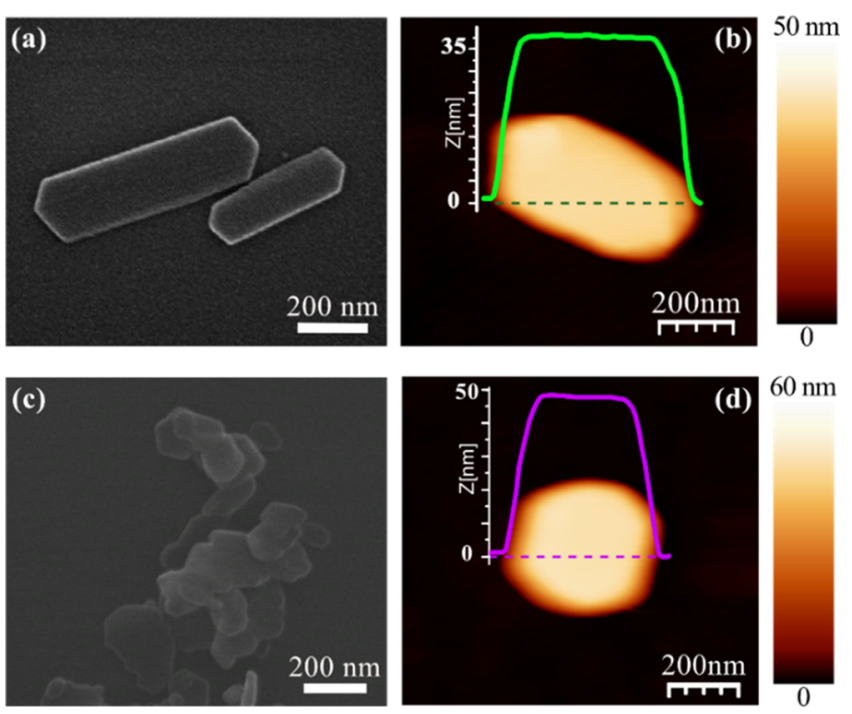

Figure 3. (a) FESEM image and (b) AFM topographic image with the height profile along the green dashed line of the nanoplate from the CP1n sample and (c) FESEM image and (d) AFM topographic image with the height profile along the pink dashed line of the nanoplate from the CP2n sample.

Stability of CP1n and CP2n in Water and Culture Media. The evaluation of the lability of the coordination bonds of CP1n and CP2n in biological media is an interesting aspect since its knowledge can be turned into a suitable tool for new drug design. Thus, the response to biological media is a determining aspect to use these compounds as cell-releasing molecules. For these reasons, we carried out the chemical stability studies of the synthesized CP1n and CP2n in water at different times and pHs and in Dulbecco's Modifed Eagle's Medium (DMEM) and Roswell Park Memorial Institute (RPMI) culture media used in the cell culture studies. The stability studies were evaluated by SEM, IR, ICP-MS, and PXRD. The studies carried out in water were done at physiological $\mathrm{pHs}$ ( $\mathrm{pHs}$ ranges $4-7$ ) and time (from 0 to 1 month). The studies showed that both NCPs are insoluble in water at $25{ }^{\circ} \mathrm{C}$, displaying similar behavior. The obtained results confirm that neither are the chemical structures of CP1n and CP2n altered under these experimental conditions (Figures S8-S13) nor are their morphologies and dimensions.

On the contrary, the treatment of CP1n and CP2n with serum-supplemented DMEM and RPMI, at $\mathrm{pH} 7.2$, causes their immediate hydrolysis and dissolution (see Material and Methods section). 
In order to get insights into these hydrolysis processes, first, the amount of $\mathrm{Cu}(\mathrm{II})$ released in water and biological serumsupplemented media was quantified by ICP-MS (Table S7).

CP1n and CP2n show similar behavior in water and different biological media (DMEM and RPMI) (Table S7). The amount of $\mathrm{Cu}$ (II) detected in solution corresponds to 30 (CP1) and 40 (CP2) $\mathrm{mg} \mathrm{L}^{-1}$ in water and 20 (CP1) and 31 (CP2) $\mathrm{mg} \mathrm{L}^{-1}$ in the biological media, regardless of the incubation times (no variations between $5 \mathrm{~min}$ and $48 \mathrm{~h}$ ). These data suggest that the transformation of CP1n and CP2n in biological media probably leads to new copper species forming and, eventually, other organic molecules. Furthermore, these data confirm that both CPs release a similar amount of $\mathrm{Cu}$ (II) in solution; therefore, the difference in the hydrolysis between both CPs is based on the so-formed species in solution.

Indeed, CP1n is partially transformed into a light green coordination compound with the formula [Cu$\left.(\mathrm{UAcO})_{2}\left(\mathrm{H}_{2} \mathrm{O}\right)_{4}\right] \cdot \mathrm{H}_{2} \mathrm{O}^{35}$ after $48 \mathrm{~h}$ in DMEM or RPMI (Scheme 2 and Figure S14). It is important to mention that

Scheme 2. (Top) Transformation of CP1n into the Coordination Complex $\left[\mathrm{Cu}(\mathrm{UAcO})_{2}\left(\mathrm{H}_{2} \mathrm{O}\right)_{4}\right] \cdot \mathrm{H}_{2} \mathrm{O}(\mathrm{Cu}(\mathrm{II})$ Complex) and $\mathrm{Cu}(\mathrm{I})$ Species among the Original Building Blocks in the Culture Media DMEM and RMPI; (Bottom) Transformation of CP2n in Its Building Blocks and Different $\mathrm{Cu}(\mathrm{II})$ and $\mathrm{Cu}(\mathrm{I})$ Species in the Culture Media DMEM and RMPI

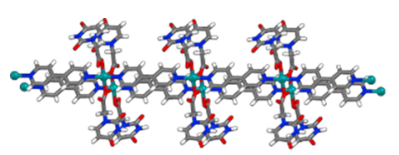

CP1n

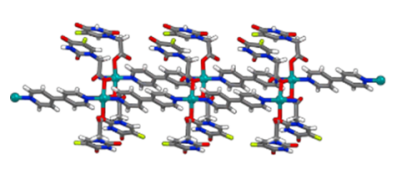

CP2n

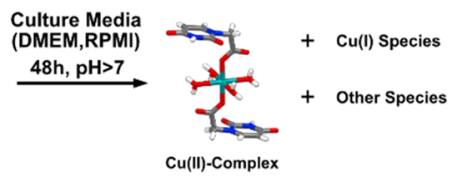
Culture Media
(DMEM,RPMI) $\stackrel{48 \mathrm{~h}, \mathrm{pH}>7}{\longrightarrow} \mathrm{Cu}(\mathrm{l})$ Species + Other Species this $\mathbf{C u}(\mathrm{II})$-complex is not soluble in biological media. However, the mechanism of the $\left[\mathrm{Cu}(\mathrm{UAcO})_{2}\left(\mathrm{H}_{2} \mathrm{O}\right)_{4}\right] \cdot \mathrm{H}_{2} \mathrm{O}$ formation is still unknown, but it should involve the breakage of the $\mathrm{Cu}-\mathrm{N}$ coordination bonds corresponding to $4,4^{\prime}$ bipyridine and its substitution by water molecules from the media.

On the other hand, in the hydrolysis of CP2n in DMEM and RPMI, we are not able to isolate the $\left[\mathrm{Cu}(\mathrm{FUA})_{2}\left(\mathrm{H}_{2} \mathrm{O}\right)_{4}\right] \cdot \mathrm{H}_{2} \mathrm{O}$ under similar conditions. The different hydrolysis behaviors observed for CP1n and CP2n in biological media versus their similar behaviors in water suggests a significant contribution of some of the components (amino acids, vitamins, or salts) present in these media.

Additionally, we have evaluated the behavior of CP1n and CP2n in the serum-free DMEM and RPMI media and, on the other hand, with each of the supplements $(10 \%(\mathrm{v} / \mathrm{v})$ fetal bovine serum (FBS), $2 \mathrm{mM}$ L-glutamine, and $1 \%$ penicillin/ streptomycin). The results show that CP1n and CP2n in biological media hydrolyze in both serum-free media but not in the supplements alone.

The characterization in the biological media of the possible species that can be formed is very complicated due to the large number of components of each media (Scheme 2). However, a cyclic voltammetry study of CP1n and CP2n in both DMEM and RPMI also shows the reduction of $\mathrm{Cu}(\mathrm{II})$ (Figure 4,
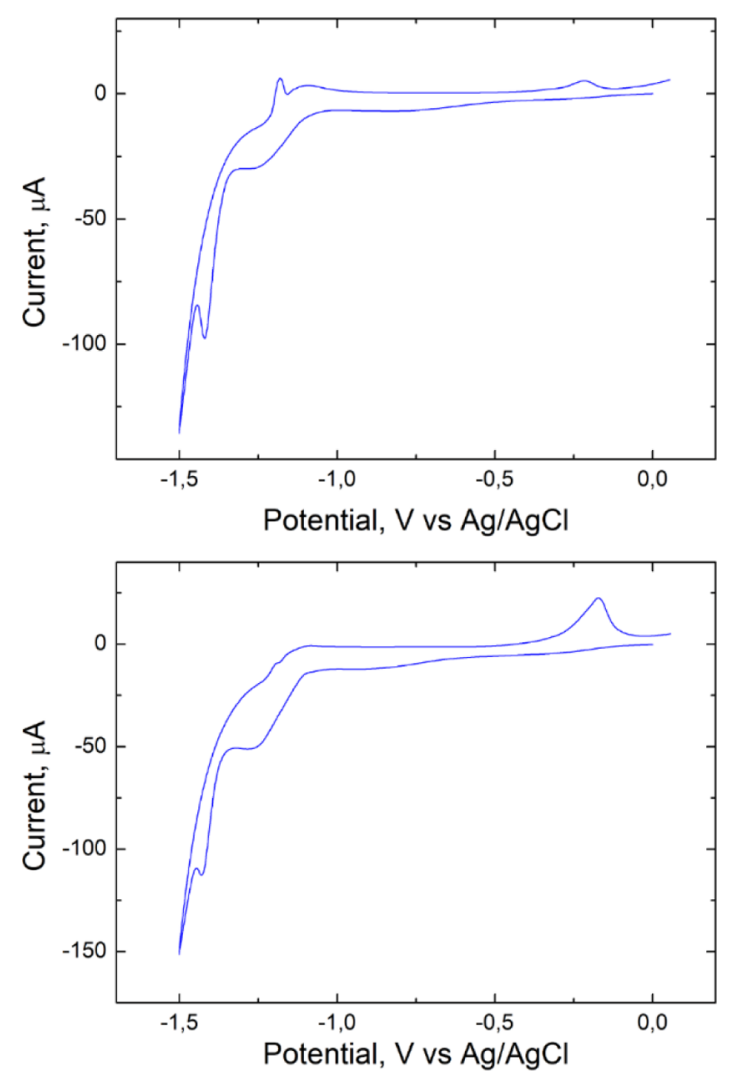

Figure 4. Cyclic voltammetry at $0.1 \mathrm{~V} / \mathrm{s}$ of CP1n (up) and CP2n (down) in DMEM.

Schemes 2 and S15). Both compounds exhibit very similar behavior despite the biological medium. The reduction takes place in two steps; the first one is quasi-reversible, at $-1.25 \mathrm{~V}$ versus $\mathrm{Ag} / \mathrm{AgCl}$, and the second one is completely irreversible, at ca. $-1.42 \mathrm{~V}$ versus $\mathrm{Ag} / \mathrm{AgCl}$. When the potential sweep covers the second component, the first peak's reoxidation is lost, and a sharp, small oxidation peak at $c a .-1.2 \mathrm{~V}$, which seems to be due to a species adsorbed on the electrode, appears. This small peak is somewhat bigger for CP1n. Further oxidation of reduction products is observed at a much more positive potential $(\mathrm{ca} .-0.2 \mathrm{~V})$.

Cell Culture Experiments. All the data previously mentioned lead us to study the viability of CP1n, CP2n, the $\mathrm{Cu}(\mathrm{II})$-complex, and the building blocks, UAcOH, 5$\mathrm{FUAcOH}, \mathrm{Cu}(\mathrm{AcO})_{2}$, and 4,4' -bipyridine in human pancreatic adenocarcinoma (Panc-1) and human uveal melanoma (Mel202) cells at different concentrations (Figures 5 and S16-S20).

A cytotoxicity assay was performed using the dye resazurin. This compound is usually employed to analyze the percentage of viable cells since it is an indicator of their active metabolism. In this sense, Mel202 and Panc-1 cells were treated with CP1n and $\left[\mathrm{Cu}(\mathrm{UAcO})_{2}\left(\mathrm{H}_{2} \mathrm{O}\right)_{4}\right] \cdot \mathrm{H}_{2} \mathrm{O}(\mathrm{Cu}(\mathrm{II})$-complex $)$ at different concentrations, and the results were analyzed $48 \mathrm{~h}$ after treatment.

On the one hand, CP1n produced a slight reduction in cell viability at $200 \mu \mathrm{M}$ to 88 and $83 \%$, respectively (Figure 5a,b, 

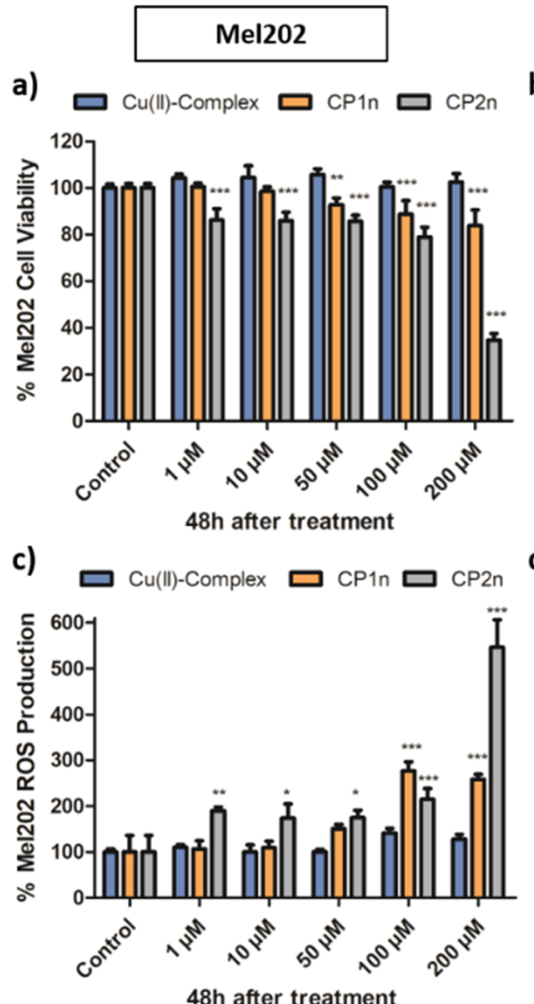

b)
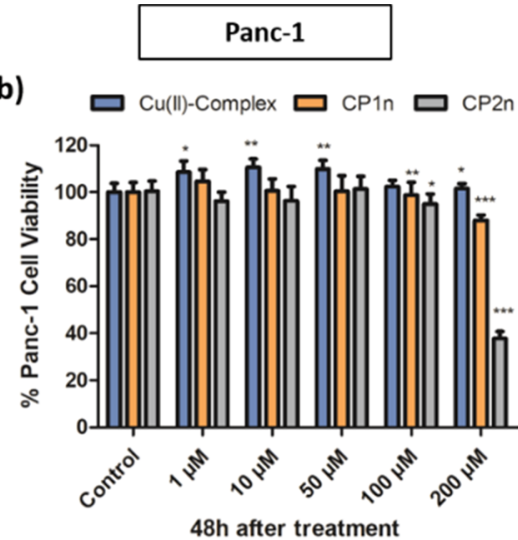

d)

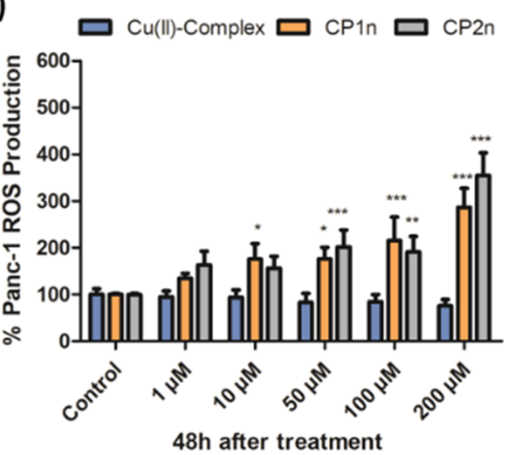

Figure 5. Cell viability and ROS production studies on (a,c) Mel202 and (b,d) Panc-1 cells at $48 \mathrm{~h}$ after treatment with different concentrations $(1-200 \mu \mathrm{M})$ of the Cu(II)-complex (blue), CP1n (orange), and CP2n (gray). ANOVA Tukey's test (each group $v s$ control). $* P<0.01, * * P<$ 0.001 , and $* * * P<0.0001$ was used for the statistical analysis.

orange bars). On the other hand, remarkably, the cell viability assay in Mel202 and Panc-1 obtained from direct incubation with $\left[\mathrm{Cu}(\mathrm{UAcO})_{2}\left(\mathrm{H}_{2} \mathrm{O}\right)_{4}\right] \cdot \mathrm{H}_{2} \mathrm{O}(\mathrm{Cu}(\mathrm{II})$-complex $)$ at 200 $\mu \mathrm{M}$ (Figure $5 \mathrm{a}, \mathrm{b}$, blue bars) shows less toxicity than direct incubation with CP1n (Figure 5a,b, orange bars) at the same concentration.

The reduction of copper(II) in biological media, observed in the cyclic voltammetry study, must be accompanied by oxidation phenomena. For this reason, to further study the effect of CP1n in the cell, we evaluated the production of ROS that influences cell toxicity. ${ }^{36}$ Thus, ROS production was studied using the standard probe $2^{\prime}, 7^{\prime}$-dichlorofluorescein $\left(\mathrm{H}_{2} \mathrm{DCFDA}\right)$ at $48 \mathrm{~h}$ after the treatment with different concentrations of $\mathrm{CP1n}$. The result showed that the $\mathbf{C u}(\mathrm{II})$ complex did not produce a significant difference in ROS generation compared to the control. However, CP1n increased the ROS level almost 3 times in both cells (Figure 5c,d). It is known that an excess of ROS can cause damage to cell organelles, which leads to cell death. ${ }^{37}$ Therefore, the increase in the ROS generation could be related to the cytotoxicity of CP1n.

The fact that CP1n suffers a transformation in the biological media and the non-significant cytotoxicity showed by the building blocks (the copper salt, $\mathrm{UAcOH}$, and 4,4' -bipyridine) (Figures S16 and S17) or by the final $\mathbf{C u}(\mathrm{II})$-complex encouraged us to introduce a small but crucial change in CP1n.

As the structure of CP1n contains free uracil groups along the chain, the idea is to interchange this uracil by 5-FU, a crucial antitumor drug, to obtain the isostructural CP2n. This small and essential change should imply a substantial improvement in cytotoxicity, given that uracil-1 acetic acid is innocuous. To anchor the 5-FU moiety correctly to the $\mathrm{Cu}$ (II) metal ion, 5-FUAcOH has been used. The terminal carboxyl group in 5-FUAcOH gives the molecule charged at physiological conditions, making it lightly more hydrophilic and more polar than 5-FU. As a result, 5-FUAcOH cannot diffuse well through the lipid core of the plasma membrane by itself. These characteristics reduce 5-FUAcOH's cytotoxicity compared to 5-FU (Figure S18). However, recent research has described that the cytotoxic effect of 5-FUAcOH was enhanced after being conjugated to biocompatible nanoparticles. ${ }^{38}$

As both CPs present similar behaviors in the media, the objective is to verify if the transformation of the new CP2 $n$ in biological media produces an increase in cytotoxicity and ROS due to the presence of the new building block. In this sense, Mel202 and Panc-1 cells were treated with CP2n at distinct concentrations. The results obtained in both cells showed an outstanding increase in cell cytotoxicity at $200 \mu \mathrm{M}$ (37 and $34 \%$ cell viability, respectively) compared to the $\mathbf{C u}(\mathrm{II})$ complex and CP1n (Figure 5a,b). Interestingly, ROS levels also produce a significant increase of up to 4-5 times.

This remarkable increase in ROS production could be the main cause of the increased toxicity in both cell lines (Figure $5 c, d)$. These better results show the ability of CP2n to distribute 5-FUAcOH to the cancer cells as a consequence of the synergy produced by the transformations observed in biological media for the CPs, such as the reduction of $\mathrm{Cu}$ (II) observed in the cyclic voltammetry and the introduction of 5$\mathrm{FuAcOH}$ as a ligand.

To conclude, the conjugation of 5-FUAcOH with $\mathrm{Cu}(\mathrm{II})$ in CP2n is key to increasing the cytotoxic potential of this antitumor agent, Mel202, and Panc-1 cells treated with a combination of CP1n + 5-FU and CP1n + 5-FUAcOH. In 
these cases, the cytotoxicity detected corresponded to that of the free drugs (Figure S19), which shows that 5-FUAcOH needs to be anchored to the $\mathrm{CP}$ to benefit from its presence.

A comparison of Mel202 and Panc-1 cell viabilities after $48 \mathrm{~h}$ of treatment with CP2n $200 \mu \mathrm{M}$ and the building blocks at the equivalent concentrations is shown in Figure S20.

\section{EXPERIMENTAL SECTION}

Reagents and solvents were acquired from standard chemical suppliers and employed as received: 4,4'-bipyridyl (4,4'-bipy) $98 \%$, uracil, and $\alpha$-chloroacetic acid (Sigma-Aldrich); copper(II) acetate monohydrate, copper(II) nitrate trihydrate, hydrochloric acid, and sodium hydroxide (Scharlab); potassium hydroxide (LabKem); and bromoacetic acid and 5-FU (Acros). The ligands $\mathrm{UAcOH}$ and 5-FUAcOH were synthesized as described in the literature. ${ }^{39,40}$

The methods used for the characterization of the compounds and the measurements of their magnetic and electrochemical properties as well as the microscopies used in the morphological study are detailed in the Supporting Information (Section S1).

(CCDC 2064122-2064123 contains the supplementary crystallographic data for this paper. These data can be obtained free of charge from The Cambridge Crystallographic Data Centre via www.ccdc. cam.ac.uk/data request/cif).

Bulk Synthesis of $\left[\mathrm{Cu}_{2}(\mathrm{UACO})_{4}\left(4,4^{\prime}-\text { bipy }\right)_{2}\right]_{n} \cdot 3 \mathrm{H}_{2} \mathrm{O}$ (CP1). A mixture of $\mathrm{Cu}\left(\mathrm{NO}_{3}\right)_{2} \cdot 3 \mathrm{H}_{2} \mathrm{O}(100 \mathrm{mg}, 0.41 \mathrm{mmol}), \mathrm{UAcOH}(141 \mathrm{mg}$, $0.82 \mathrm{mmol})$, and $4,4^{\prime}$-bipy $(65 \mathrm{mg}, 0.41 \mathrm{mmol})$ was stirred $(10 \mathrm{~min})$ in water $(18 \mathrm{~mL})($ initial $\mathrm{pH}=2.30)$ at $25^{\circ} \mathrm{C}$. The purple suspension obtained was subjected to hydrothermal conditions $\left(120^{\circ} \mathrm{C}\right.$ for 3 days) and cooled down to $30{ }^{\circ} \mathrm{C}$ at a rate of $0.05{ }^{\circ} \mathrm{C} \mathrm{min}{ }^{-1}$ (final pH $=2.57$ ). Purple and turquoise crystals were obtained and separated by hand. The turquoise crystals were identified as a previously reported $\mathrm{CP}$ with the formula $\left[\mathrm{Cu}_{2}(\mathrm{UAcO})_{2}\left(\mathrm{C}_{2} \mathrm{O}_{4}\right)\left(4,4^{\prime}\right.\right.$-bipy $\left.)\right] \cdot 2 \mathrm{H}_{2} \mathrm{O} .{ }^{10}$ The purple crystals were washed $\left(\mathrm{H}_{2} \mathrm{O}\right)$ and dried in air $(190 \mathrm{mg}, 43 \%$ yield based on $\mathrm{Cu}$ ). Anal. Calcd for $\mathrm{C}_{44} \mathrm{H}_{42} \mathrm{Cu}_{2} \mathrm{~N}_{12} \mathrm{O}_{19}$ (CP1): C, 45.17; H, 3.59; N, 14.37. Found: C, 44.84; H, 3.64; N, 14.06 and IR selected data (ATR) $\nu\left(\mathrm{cm}^{-1}\right): 3450(\mathrm{w}), 3100(\mathrm{w}), 3053(\mathrm{w}), 1666$ (s), $1630(\mathrm{~s}), 1610(\mathrm{~s}), 1467(\mathrm{~m}), 1391(\mathrm{~s}), 1345(\mathrm{~m}), 1300(\mathrm{~m})$, $1239(\mathrm{~m}), 1203(\mathrm{~m}), 1076(\mathrm{w}), 965(\mathrm{w}), 812(\mathrm{~s}), 756(\mathrm{~m}), 721(\mathrm{~m})$, $644(\mathrm{~m})$. The X-ray diffraction pattern of the purple crystals matches the diffraction pattern simulated from the structure obtained by single-crystal X-ray diffraction for CP1 (Figure S1).

Synthesis of Nanostructured $\left[\mathrm{Cu}_{2}(\mathrm{UACO})_{4}\left(4,4^{\prime}-\text {-bipy }\right)_{2}\right]_{n}$. $3 \mathrm{H}_{2} \mathrm{O}$ (CP1n). $\mathrm{NaOH}(33 \mathrm{mg}, 0.82 \mathrm{mmol})$ dissolved in water (3 $\mathrm{mL})$ was added over a water $(4 \mathrm{~mL})$ suspension of $\mathrm{UAcOH}(141 \mathrm{mg}$, $0.82 \mathrm{mmol}$ ). The resulting colorless solution was added while stirring at $5{ }^{\circ} \mathrm{C}$ to a water suspension $(4 \mathrm{~mL})$ of $4,4^{\prime}$-bipy $(65 \mathrm{mg}, 0.41$ $\mathrm{mmol}$ ). The initial white suspension turned into a purple colloid upon the addition of $3 \mathrm{~mL}$ of an aqueous solution of $\mathrm{Cu}\left(\mathrm{CH}_{3} \mathrm{COO}\right)_{2} \cdot \mathrm{H}_{2} \mathrm{O}$ $(82 \mathrm{mg}, 0.41 \mathrm{mmol})$. The purple colloid was stirred at $1200 \mathrm{rpm}$ for 5 min, centrifuged $(3 \mathrm{~min})$ at $5000 \mathrm{rpm}$, and washed with $56 \mathrm{~mL}$ of Milli-Q water. The solid was dried in air $(180 \mathrm{mg}$, 38\% yield based on $\mathrm{Cu}$ ). Anal. Calcd for $\mathrm{C}_{44} \mathrm{H}_{42} \mathrm{Cu}_{2} \mathrm{~N}_{12} \mathrm{O}_{19}$ (CP1n): C, 45.17; H, 3.59; N, 14.37. Found: C, 44.81; H, 3.67; N, 14.14 and IR selected data (ATR) $\nu\left(\mathrm{cm}^{-1}\right): 3490(\mathrm{w}), 3104(\mathrm{w}), 3059(\mathrm{w}), 1676(\mathrm{~s}), 1626(\mathrm{~s})$, $1606(\mathrm{~s}), 1433(\mathrm{~m}), 1390(\mathrm{~s}), 1348(\mathrm{~m}), 1297(\mathrm{~m}), 1233(\mathrm{~m}), 1203$ $(\mathrm{m}), 1075(\mathrm{w}), 967(\mathrm{w}), 813(\mathrm{~s}), 762(\mathrm{~m}), 727(\mathrm{~m}), 642(\mathrm{~m})$. PXRD data confirm that the obtained solid corresponds to CP1 (Figure S2).

Bulk Synthesis of $\left[\mathrm{Cu}_{2}(5-\mathrm{FUAcO})_{4}\left(4,4^{\prime} \text {-bipy }\right) 2\right]_{n} \cdot 4 \mathrm{H}_{2} \mathrm{O}(\mathrm{CP} 2)$. $\mathrm{Cu}\left(\mathrm{NO}_{3}\right)_{2} \cdot 3 \mathrm{H}_{2} \mathrm{O}(100 \mathrm{mg}, 0.41 \mathrm{mmol}), 5-\mathrm{FUAcOH}(150 \mathrm{mg}, 0.82$ $\mathrm{mmol})$, and 4,4'-bipy $(65 \mathrm{mg}, 0.41 \mathrm{mmol})$ were stirred together in water $(18 \mathrm{~mL}$, initial $\mathrm{pH}=2.68)$ at $25{ }^{\circ} \mathrm{C}$ for $10 \mathrm{~min}$. The purple suspension obtained was subjected to hydrothermal conditions (120 ${ }^{\circ} \mathrm{C}$ for 2 days) and cooled down to $30{ }^{\circ} \mathrm{C}$ at a rate of $0.05{ }^{\circ} \mathrm{C} \mathrm{min}^{-1}$ (final $\mathrm{pH}=2.54$ ). Low amounts of unstable yellow crystals and deep purple crystals were obtained. The purple crystals were separated by hand, washed with water, and dried in air $(40 \mathrm{mg}, 7.3 \%$ yield based on $\mathrm{Cu}$ ). Anal. Calcd for $\mathrm{C}_{44} \mathrm{H}_{48} \mathrm{Cu}_{2} \mathrm{~N}_{12} \mathrm{O}_{24} \mathrm{~F}_{4}$ (CP2): C, 39.67; H, 3.61; N, 12.62. Found: C, 40.52; H, 3.66; N, 11.93 and IR selected data $($ ATR $) \nu\left(\mathrm{cm}^{-1}\right): 3498(\mathrm{w}), 3171(\mathrm{w}), 3063(\mathrm{w}), 2823(\mathrm{w}), 1700(\mathrm{~s})$, $1661(\mathrm{~s}), 1635$ (s), $1602(\mathrm{~s}), 1495(\mathrm{w}), 1475(\mathrm{w}), 1413(\mathrm{~m}), 1398$ (s), $1381(\mathrm{~s}), 1368(\mathrm{~s}), 1342(\mathrm{~m}), 1320(\mathrm{~m}), 1300(\mathrm{~s}), 1241(\mathrm{~s})$, $1190(\mathrm{w}), 1144(\mathrm{~m}), 1073(\mathrm{~m}), 985(\mathrm{~m}), 898(\mathrm{~m}), 813(\mathrm{~s}), 798(\mathrm{~s})$, $762(\mathrm{~m}), 698(\mathrm{~m}), 642(\mathrm{~m})$. X-ray diffraction confirms that purple crystals belong to CP2 (Figure S3).

Synthesis of Nanostructured $\left[\mathrm{Cu}_{2}(5-\mathrm{FUAcO})_{4}\left(4,4^{\prime}-\mathrm{bipy}\right)_{2}\right]_{n^{*}}{ }^{*}$ $4 \mathrm{H}_{2} \mathrm{O}$ (CP2n). A mixture of 5-FUAcOH $(150 \mathrm{mg}, 0.82 \mathrm{mmol})$ and $\mathrm{NaOH}(32 \mathrm{mg}, 0.82 \mathrm{mmol}$ ) in water (total volume $7 \mathrm{~mL}$ ) was added under stirring at $5{ }^{\circ} \mathrm{C}$ to a water suspension $(4 \mathrm{~mL})$ of $4,4^{\prime}$-bipy $(65$ $\mathrm{mg}, 0.41 \mathrm{mmol})$. After the addition of $3 \mathrm{~mL}$ of an aqueous solution of $\mathrm{Cu}\left(\mathrm{NO}_{3}\right)_{2} \cdot 3 \mathrm{H}_{2} \mathrm{O}(100 \mathrm{mg}, 0.41 \mathrm{mmol})$, the resulting white suspension turned into a purple colloid, which was stirred at 1200 $\mathrm{rpm}(5 \mathrm{~min})$, centrifuged at $5000 \mathrm{rpm}(3 \mathrm{~min})$, and washed with Milli-Q water $(56 \mathrm{~mL})$. The solid was dried in air $(78 \mathrm{mg}, \%$ yield based on $\mathrm{Cu}$ ). Anal. Calcd for $\mathrm{C}_{44} \mathrm{H}_{48} \mathrm{Cu}_{2} \mathrm{~N}_{12} \mathrm{O}_{24} \mathrm{~F}_{4}$ (CP2n): C, 39.67; $\mathrm{H}, 3.61 ; \mathrm{N}, 12.62$. Found: $\mathrm{C}, 39.67 ; \mathrm{H}, 3.58 ; \mathrm{N}, 12.42$ and IR selected data $($ ATR $) \nu\left(\mathrm{cm}^{-1}\right): 3492(\mathrm{w}), 3104(\mathrm{w}), 3059(\mathrm{w}), 1675(\mathrm{~s}), 1626$ (s), $1603(\mathrm{~s}), 1431(\mathrm{~m}), 1389(\mathrm{~s}), 1348(\mathrm{~m}), 1297(\mathrm{~m}), 1233(\mathrm{~m})$, $1201(\mathrm{~m}), 1075(\mathrm{w}), 967(\mathrm{w}), 813(\mathrm{~s}), 764(\mathrm{~m}), 727(\mathrm{~m}), 641(\mathrm{~m})$. PXRD data confirm that the solid corresponds to CP2 (Figure S4).

Stability of CP1n and CP2n in Water. The initial $\mathrm{pH}$ value of ca. 5.7 for CP1n and CP2n colloids was readjusted upon addition of (i) an aqueous solution of $\mathrm{NaOH} 0.01 \mathrm{M}$ until reaching $\mathrm{pH}=7$ and (ii) an aqueous solution of $\mathrm{HCl} 0.01 \mathrm{M}$ until reaching $\mathrm{pH}=4$. The obtained suspensions were analyzed by PXRD, IR, and SEM, showing that both coordination compounds are chemically and morphologically stable without significant changes (Figures S8, S9, S11, and S12).

Freshly prepared colloidal suspensions of both samples (CP1n and CP2n) $(t=0)$ were stored in closed vials at $25{ }^{\circ} \mathrm{C}$ for 1 month (initial and final $\mathrm{pH}=5.7)$. Their stability in solution within time was also evaluated with SEM and PXRD. The studies show identical PXRDs and do not show evident morphological changes (Figures S10 and S13).

The behavior of CP1n and $\mathbf{C P 2 n}$ in water was evaluated by ICPMS, measuring the amount of copper(II) ions at different reaction times ( $5 \mathrm{~min}, 15 \mathrm{~min}, 1 \mathrm{~h}, 24 \mathrm{~h}$, and $48 \mathrm{~h}$ ). For this study, five samples were prepared by addition of $100 \mu \mathrm{L}$ of NCPs to $900 \mu \mathrm{L}$ of Milli-Q water and centrifuged at different time points using standard dialysis centrifugal filters (Amicon $10 \mathrm{kDa}$ ) to remove the solid (Table S7).

Cell Culture. Panc-1 cells were obtained from American Type Culture Collection (ATCC), and human uveal melanoma (Mel202) cells were provided by the University of California, San Francisco, Dr. Susana Ortiz-Urda laboratory.

Panc-1 cells were grown in DMEM, while Mel202 cells were cultured in RPMI 1640 medium. Both cell culture mediums were supplemented with $10 \%$ (v/v) FBS, $2 \mathrm{mM}$ L-glutamine, and $1 \%$ penicillin/streptomycin. The experiments were done on subconfluent cells incubated under standard conditions $\left(37^{\circ} \mathrm{C}, 5 \% \mathrm{CO}_{2}\right)$.

Stability of CP1 $n$ and CP2n in Culture Media. Since the cells are grown in the culture media DMEM and RPMI supplemented with $10 \%$ (v/v) FBS, $2 \mathrm{mM}$ L-glutamine, and 1\% penicillin/streptomycin (serum-supplemented medium), studies were carried out to analyze the stability of CP1n and CP2n in the cell culture media.

$100 \mu \mathrm{L}$ of CP1n or CP2n was incubated with $900 \mu \mathrm{L}$ of the serumsupplemented medium (DMEM or RPMI). A blank sample using just water instead of the serum-supplemented media at room temperature was also studied. It becomes clear that only after a few seconds in the medium, CP1n and CP2n underwent a chemical transformation, leading to the complete dissolution of the initial materials. The mixtures were centrifuged from $1 \mathrm{~min}$ to $1 \mathrm{~h}$ without the appearance of any solid. $48 \mathrm{~h}$ later, a light green solid appeared in the CP1n media solutions, which was characterized by PXRD as the complex $\left[\mathrm{Cu}(\mathrm{UAcO})_{2}\left(\mathrm{H}_{2} \mathrm{O}\right)_{4}\right] \cdot 2 \mathrm{H}_{2} \mathrm{O}(\mathrm{Cu}(\mathrm{II})$-complex) (Figure $\mathrm{S} 14$ ).

The behavior of CP1n and CP2n in the supplemented media was evaluated by ICP-MS, measuring the amount of copper(II) ions at different reaction times ( $5 \mathrm{~min}, 15 \mathrm{~min}, 1 \mathrm{~h}, 24 \mathrm{~h}$, and $48 \mathrm{~h}$ ) under the same experimental conditions mentioned above. The samples were centrifuged using standard dialysis centrifugal filters (Amicon $10 \mathrm{kDa}$ ) to remove the solid (Table S7). 
Cytotoxicity Assay. The uveal melanoma (Mel 202) cell line and pancreatic cancer cells (Panc-1) were seeded in 24-well plates and incubated at standard conditions. Then, the cells were incubated with the corresponding compound for $24 \mathrm{~h}$ at different concentrations: CP1n, CP2n, 4,4'-bipy, and $\mathrm{UAcOH}(1-200 \mu \mathrm{M}) ; \mathrm{Cu}(\mathrm{AcO})_{2}$ $(2.04-408 \mu \mathrm{M})$; and 5-FU and 5-FUAcOH $(3.9-788 \mu \mathrm{M})$. After incubation, the culture medium was taken away, and the cells were washed with PBS $1 \times .48 \mathrm{~h}$ after treatment, using resazurin assay following the manufacturer's protocol, toxicity was measured. ${ }^{41}$ The cell culture medium was replaced by a fresh one containing $1 \%$ resazurin solution $\left(1 \mathrm{mg} \mathrm{mL}^{-1}\right.$ in PBS). In addition, cells were incubated at $37^{\circ} \mathrm{C}, 5 \% \mathrm{CO}_{2}$ for $3 \mathrm{~h}$ more. A microplate reader $\left(\lambda_{\text {exc }}=\right.$ $550 / 20 \mathrm{~nm}, \lambda_{\mathrm{em}}=590 / 20 \mathrm{~nm}$ ) was used to measure the fluorescence. Data corresponded to mean values \pm standard deviation. For statistical calculations, one-way ANOVA and Tukey's Test in $\mathrm{R}$ Commander software was used. ${ }^{42} P$ values $<0.05(*),<0.01(* *)$, and $<0.001(* * *)$ were considered as statistically significant (Figures S15-S17).

ROS Generation Assay. Cells were plated in 96-well plates $(15 \times$ $10^{3}$ cells well $^{-1}$ ) and incubated at standard conditions. After that, the cells were treated $(24 \mathrm{~h})$ with different concentrations of CP1n and CP2n, washed twice with fresh medium, and further incubated for 24 h. Then, cells were incubated with $5 \mu \mathrm{M} \mathrm{H}_{2} \mathrm{DCFDA}$ for $30 \mathrm{~min}$ at 37 ${ }^{\circ} \mathrm{C}, 5 \% \mathrm{CO}_{2}$. Finally, cells were washed with $1 \times \mathrm{PBS}(\mathrm{pH} 7.4)$. Again, a microplate reader $\left(\lambda_{\text {exc }}=485 / 20 \mathrm{~nm}, \lambda_{\mathrm{em}}=535 / 20 \mathrm{~nm}\right)$ was used to measure the fluorescence. Values were normalized with the results of the cell viability assay. Data represent the mean values \pm standard deviation. For statistical calculations, one-way ANOVA and Tukey's Test in R Commander software was used. ${ }^{42} P$ values $<0.05(*),<0.01$ $(* *)$, and $<0.001(* * *)$ were considered as statistically significant (Figure 5).

\section{CONCLUSIONS}

Previous studies have shown great interest in synthesizing $\mathrm{Cu}$ (II) NCPs with modified nucleobases and molecular recognition capabilities because of their potential use as nanocarriers for drugs or molecules of biological interest. ${ }^{15}$ However, this work shows a different perspective of the potential use of nanostructured CPs generating active species in a medium upon hydrolysis. Thus, we have demonstrated that a suitable combination of building blocks forming the $\mathrm{CP}$ networks allows their use as precursor nanocarriers of active drugs.

We have prepared water colloids of two CPs based on $\mathrm{Cu}(\mathrm{II})$ decorated with 5-fluorouracil-1-acetate and uracil-1acetate as terminal ligands and studied their hydrolysis in biological media. We confirmed that these reactions provoke molecular reorganizations leading to the formation of soluble copper species and organic molecules.

Interestingly, the cytotoxic cell studies show that while CP1n shows a decrease in the cell viability of $c a .17 \%$, its molecular precursors and the $\mathrm{Cu}(\mathrm{II})$ complex that is formed in the media do not show toxicity under similar conditions. Furthermore, CP1n produces an enhancement of ROS levels in cells three times higher than ROS levels in cells. This observation correlates well with the reduction phenomena observed in CV studies and suggests that the cytotoxicity observed for CP1n produces oxidative stress in a similar way to that described for related $\mathrm{Zn}-\mathrm{MOF}$ s. $^{30}$

These observations suggest the design of an isostructural CP to improve the cytotoxic activity, in which the difference is the substitution of uracil-1-acetate by 5-fluorouracil-1-acetate as the terminal ligand since 5-fluorouracil-1-acetate is a derivative of the essential anticancer agent 5-FU. ${ }^{43}$ The new CP2n presents a similar behavior in the biological media to that of CP1n. However, it shows both a considerable increase in cellular toxicity (up to 66\%) and a significant increase in ROS species' formation (five times the level of ROS in cells). Therefore, because the copper species produced by the hydrolysis of CP1n and CP2n are similar, the difference in toxicity is ascribed to the organic species generated in the medium and the reduction phenomena. Therefore, we believe that the presence of species containing the 5-FU moiety in the hydrolysis of $\mathbf{C P 2} \mathbf{n}$ causes a significant increase in its cytotoxicity.

In summary, this work suggests a novel approach for designing therapeutic drugs based on the rational design of their structures in which their hydrolysis in biological media generates active drugs. However, it also takes advantage of the production of biocompatible water colloids based on nanostructures of CPs.

\section{ASSOCIATED CONTENT}

\section{Supporting Information}

The Supporting Information is available free of charge at https://pubs.acs.org/doi/10.1021/acsami.1c11612.

Methods; structural characterization of CP1 and CP2; stability studies of CP1n and CP2n; and biological studies (PDF)

Crystallographic data (CIF)

\section{AUTHOR INFORMATION}

\section{Corresponding Authors}

Álvaro Somoza - Instituto Madrileño de Estudios Avanzados en Nanociencia (IMDEA Nanociencia), Madrid 28049, Spain; $\odot$ orcid.org/0000-0001-9873-435X; Email: alvaro.somoza@imdea.org

Pilar Amo-Ochoa - Departamento de Química Inorgánica, Universidad Autónoma de Madrid, Madrid 28049, Spain; ○ orcid.org/0000-0002-1952-1020; Email: pilar.amo@ uam.es

\section{Authors}

Verónica G. Vegas - Departamento de Química Inorgánica, Universidad Autónoma de Madrid, Madrid 28049, Spain

Ana Latorre - Instituto Madrileño de Estudios Avanzados en Nanociencia (IMDEA Nanociencia), Madrid 28049, Spain

María Luisa Marcos - Departamento de Química, Universidad Autónoma de Madrid, Madrid 28049, Spain

Carlos J. Gómez-García - Instituto de Ciencia Molecular (ICMol), Departamento de Química Inorgánica, Universidad de Valencia, Valencia 46980, Spain; 이이.org/00000002-0015-577X

Óscar Castillo - Departamento de Química Inorgánica, Universidad del País Vasco (UPV/EHU), Bilbao E-48080, Spain

Félix Zamora - Departamento de Química Inorgánica, Universidad Autónoma de Madrid, Madrid 28049, Spain; - orcid.org/0000-0001-7529-5120

Jacobo Gómez - Centro Singular en Química Biolóxica e Materiais Moleculares (CiQUS), Departamento de Química Inorgánica, Universidad de Santiago de Compostela, Santiago de Compostela 15782, Spain; $\odot$ orcid.org/0000-0002$8877-7775$

José Martínez-Costas - Centro Singular en Química Biolóxica e Materiais Moleculares (CiQUS), Departamento de Bioquímica y Biología Molecular, Universidad de Santiago de Compostela, Santiago de Compostela 15782, Spain 
Miguel Vázquez López - Centro Singular en Química Biolóxica e Materiais Moleculares (CiQUS), Departamento de Química Inorgánica, Universidad de Santiago de Compostela, Santiago de Compostela 15782, Spain

Complete contact information is available at: https://pubs.acs.org/10.1021/acsami.1c11612

\section{Notes}

The authors declare no competing financial interest.

\section{ACKNOWLEDGMENTS}

The authors thank the financial support from the Spanish Ministerio de Economía y Competitividad (PID2019108028GB-C22, PID2019-108028GB-C21, MAT2016-77608C3-1-P, MAT2016-75883-C2-1-P, MAT2016-75883-C2-2-P, MAT2016-75586-C4-4-P, and CTQ2017-87201-PAEI/ FEDER, UE) and the Generalidad Valenciana (Prometeo/ 2019/076).

\section{REFERENCES}

(1) Tăbăcaru, A.; Pettinari, C.; Galli, S. Coordination Polymers and Metal-Organic Frameworks Built up with Poly(Tetrazolate) Ligands. Coord. Chem. Rev. 2018, 372, 1-30.

(2) Batten, S. R.; Neville, S. M.; Turne, D. R. Coordination Polymers; Royal Society of Chemistry: Cambridge, 2008.

(3) Moreno-Moreno, M.; Troyano, J.; Ares, P.; Castillo, O.; Nijhuis, C. A.; Yuan, L.; Amo-Ochoa, P.; Delgado, S.; Gómez-Herrero, J.; Zamora, F.; et al. One-Pot Preparation of Mechanically Robust, Transparent, Highly Conductive, and Memristive Metal-Organic Ultrathin Film. ACS Nano 2018, 12, 10171-10177.

(4) Horcajada, P.; Gref, R.; Baati, T.; Allan, P. K.; Maurin, G.; Couvreur, P.; Férey, G.; Morris, R. E.; Serre, C. Metal-Organic Frameworks in Biomedicine. Chem. Rev. 2012, 112, 1232-1268.

(5) Gómez-Herrero, J.; Zamora, F. Coordination Polymers for Nanoelectronics. Adv. Mater. 2011, 23, 5311-5317.

(6) Amo-Ochoa, P.; Zamora, F. Coordination Polymers with Nucleobases: From Structural Aspects to Potential Applications. Coord. Chem. Rev. 2014, 276, 34-58.

(7) Vegas, V.; Villar-Alonso, M.; Gómez-García, C.; Zamora, F.; Amo-Ochoa, P. Direct Formation of Sub-Micron and Nanoparticles of a Bioinspired Coordination Polymer Based on Copper with Adenine. Polymers 2017, 9, 565.

(8) Conesa-Egea, J.; Hassanein, K.; Muñoz, M.; Zamora, F.; AmoOchoa, P. Fast and efficient direct formation of size-controlled nanostructures of coordination polymers based on copper(i)-iodine bearing functional pyridine terminal ligands. Dalt. Trans. 2018, 47, 5607-5613.

(9) Conesa-Egea, J.; Gallardo-Martínez, J.; Delgado, S.; Martínez, J. I.; Gonzalez-Platas, J.; Fernández-Moreira, V.; Rodríguez-Mendoza, U. R.; Ocón, P.; Zamora, F.; Amo-Ochoa, P. Multistimuli Response Micro- and Nanolayers of a Coordination Polymer Based on Cu 2 I 2 Chains Linked by 2-Aminopyrazine. Small 2017, 13, 1700965.

(10) Vegas, V. G.; Maldonado, N.; Castillo, O.; Gómez-García, C. J.; Amo-Ochoa, P. Multifunctional Coordination Polymers Based on Copper with Modified Nucleobases, Easily Modulated in Size and Conductivity. J. Inorg. Biochem. 2019, 200, 110805.

(11) Hu, M.; Ishihara, S.; Yamauchi, Y. Bottom-up Synthesis of Monodispersed Single-Crystalline Cyano-Bridged Coordination Polymer Nanoflakes. Angew. Chemie Int. Ed. 2013, 52, 1235-1239.

(12) Conesa-Egea, J.; Zamora, F.; Amo-Ochoa, P. Perspectives of the Smart Cu-Iodine Coordination Polymers: A Portage to the World of New Nanomaterials and Composites. Coord. Chem. Rev. 2019, 381, 65-78.

(13) Chen, B.; Keshive, M.; Deen, W. M. Diffusion and Reaction of Nitric Oxide in Suspension Cell Cultures. Biophys. J. 1998, 75, 745754.
(14) Xie, J.; Marijnissen, J.; Wang, C. Microparticles Developed by Electrohydrodynamic Atomization for the Local Delivery of Anticancer Drug to Treat C6 Glioma in Vitro. Biomaterials 2006, 27, 3321-3332.

(15) Vegas, V. G.; Lorca, R.; Latorre, A.; Hassanein, K.; GómezGarcía, C. J.; Castillo, O.; Somoza, Á.; Zamora, F.; Amo-Ochoa, P. Copper(II)-Thymine Coordination Polymer Nanoribbons as Potential Oligonucleotide Nanocarriers. Angew. Chemie Int. Ed. 2017, 56, 987-991.

(16) Maldonado, N.; Vegas, V. G.; Halevi, O.; Martínez, J. I.; Lee, P. S.; Magdassi, S.; Wharmby, M. T.; Platero-Prats, A. E.; Moreno, C.; Zamora, F.; et al. 3D Printing of a Thermo- and Solvatochromic Composite Material Based on a $\mathrm{Cu}(\mathrm{II})$-Thymine Coordination Polymer with Moisture Sensing Capabilities. Adv. Funct. Mater. 2019, 29, 1808424.

(17) Shen, S.; Wu, Y.; Li, K.; Wang, Y.; Wu, J.; Zeng, Y.; Wu, D. Versatile Hyaluronic Acid Modified AQ4N-Cu(II)-Gossypol Infinite Coordination Polymer Nanoparticles: Multiple Tumor Targeting, Highly Efficient Synergistic Chemotherapy, and Real-Time SelfMonitoring. Biomaterials 2018, 154, 197-212.

(18) Simagina, A. A.; Polynski, M. V.; Vinogradov, A. V.; Pidko, E. A. Towards Rational Design of Metal-Organic Framework-Based Drug Delivery Systems. Russ. Chem. Rev. 2018, 87, 831-858.

(19) Gao, P. F.; Zheng, L. L.; Liang, L. J.; Yang, X. X.; Li, Y. F.; Huang, C. Z. A New Type of PH-Responsive Coordination Polymer Sphere as a Vehicle for Targeted Anticancer Drug Delivery and Sustained Release. J. Mater. Chem. B 2013, 1, 3202.

(20) Brange, J. Chemical Stability of Insulin. 4. Mechanisms and Kinetics of Chemical Transformations in Pharmaceutical Formulation. Acta Pharm. Nord. 1992, 4, 209-222.

(21) Nakamura, T.; Yoshida, E.; Fujie, T.; Ogata, F.; Yamamoto, C.; Kawasaki, N.; Kaji, T. Synergistic Cytotoxicity Caused by Forming a Complex of Copper and 2,9-Dimethyl-1,10-Phenanthroline in Cultured Vascular Endothelial Cells. J. Toxicol. Sci. 2017, 42, 683687.

(22) Ahmed, M.; Lei, Z. N.; Ali, M.; Ali, S. I.; Kojima, K.; Gupta, P.; Mumtaz, M.; Yang, D. H.; Haider, S. M.; Chen, Z. S. Synthesis, Characterization and Anticancer Activity of Isonicotinylhydrazide Metal Complexes. J. Chem. Soc. Pakistan 2019, 41, 113-121.

(23) Rajendran, N.; Periyasamy, A.; Kamatchi, N.; Solomon, V. Biological Evaluation of Copper(II) Complexes on N (4)-substituted Thiosemicarbazide Derivatives and Diimine Co-Ligands Using DNA Interaction, Antibacterial and in Vitro Cytotoxicity. J. Coord. Chem. 2019, 72, 1937-1956.

(24) Mirzaahmadi, A.; Hosseini-Yazdi, S. A.; Safarzadeh, E.; Baradaran, B.; Samolova, E.; Dusek, M. New Series of Water-Soluble Thiosemicarbazones and Their Copper(II) Complexes as Potentially Promising Anticancer Compounds. J. Mol. Liq. 2019, 293, 111412.

(25) Gałczyńska, K.; Ciepluch, K.; Madej, Ł.; Kurdziel, K.; Maciejewska, B.; Drulis-Kawa, Z.; Węgierek-Ciuk, A.; Lankoff, A.; Arabski, M. Selective Cytotoxicity and Antifungal Properties of Copper(II) and Cobalt(II) Complexes with Imidazole-4-Acetate Anion or 1-Allylimidazole. Sci. Rep. 2019, 9, 9777.

(26) Hussain, A.; AlAjmi, M. F.; Rehman, M. T.; Amir, S.; Husain, F. M.; Alsalme, A.; Siddiqui, M. A.; AlKhedhairy, A. A.; Khan, R. A. Copper(II) Complexes as Potential Anticancer and Nonsteroidal Anti-Inflammatory Agents: In Vitro and in Vivo Studies. Sci. Rep. 2019, 9, 5237.

(27) Hangan, A. C.; Borodi, G.; Stan, R. L.; Páll, E.; Cenariu, M.; Oprean, L. S.; Sevastre, B. Synthesis, Crystal Structure, DNA Cleavage and Antitumor Activity of Two Copper(II) Complexes with NSulfonamide Ligand. Inorganica Chim. Acta 2018, 482, 884-893.

(28) Nordin, N.; Yahaya, B. H.; Yusop, M. R. Electrochemical Synthesis and in Vitro Cytotoxicity Study of Copper(II) Carboxylates with Different Fatty Acid Alkyl Chain Lengths. New J. Chem. 2018, 42, 15127-15135.

(29) Eixenberger, J. E.; Anders, C. B.; Hermann, R. J.; Brown, R. J.; Reddy, K. M.; Punnoose, A.; Wingett, D. G. Rapid Dissolution of 
$\mathrm{ZnO}$ Nanoparticles Induced by Biological Buffers Significantly Impacts Cytotoxicity. Chem. Res. Toxicol. 2017, 30, 1641-1651.

(30) Ruyra, À.; Yazdi, A.; Espín, J.; Carné-Sánchez, A.; Roher, N.; Lorenzo, J.; Imaz, I.; Maspoch, D. Synthesis, Culture Medium Stability, and In Vitro and In Vivo Zebrafish Embryo Toxicity of Metal-Organic Framework Nanoparticles. Chem.-Eur. J. 2015, 21, 2508-2518.

(31) Duffin, R. N.; Blair, V. L.; Kedzierski, L.; Andrews, P. C. Comparative stability, toxicity and anti-leishmanial activity of triphenyl antimony $(\mathrm{v})$ and bismuth(v) $\alpha$-hydroxy carboxylato complexes. Dalt. Trans. 2018, 47, 971-980.

(32) Mendes, R. F.; Figueira, F.; Leite, J. P.; Gales, L.; Almeida Paz, F. A. Metal-Organic Frameworks: A Future Toolbox for Biomedicine? Chem. Soc. Rev. 2020, 49, 9121-9153.

(33) Tamames-Tabar, C.; Cunha, D.; Imbuluzqueta, E.; Ragon, F.; Serre, C.; Blanco-Prieto, M. J.; Horcajada, P. Cytotoxicity of Nanoscaled Metal-Organic Frameworks. J. Mater. Chem. B 2014, 2, 262-271.

(34) Spek, A. L. Single-Crystal Structure Validation with the Program PLATON. J. Appl. Crystallogr. 2003, 36, 7-13.

(35) Amo-Ochoa, P.; Castillo, O.; Gómez-García, C. J.; Hassanein, K.; Verma, S.; Kumar, J.; Zamora, F. Semiconductive and Magnetic One-Dimensional Coordination Polymers of $\mathrm{Cu}(\mathrm{II})$ with Modified Nucleobases. Inorg. Chem. 2013, 52, 11428-11437.

(36) Gaetke, L. M.; Chow-Johnson, H. S.; Chow, C. K. Copper: Toxicological Relevance and Mechanisms. Arch. Toxicol. 2014, 88, 1929-1938.

(37) Bae, Y. S.; Oh, H.; Rhee, S. G.; Yoo, Y. D. Do. Regulation of Reactive Oxygen Species Generation in Cell Signaling. Mol. Cells 2011, 32, 491-509.

(38) Gan, B. K.; Rullah, K.; Yong, C. Y.; Ho, K. L.; Omar, A. R.; Alitheen, N. B.; Tan, W. S. Targeted Delivery of 5-Fluorouracil-1Acetic Acid (5-FA) to Cancer Cells Overexpressing Epithelial Growth Factor Receptor (EGFR) Using Virus-like Nanoparticles. Sci. Rep. 2020, 10, 16867.

(39) Xiong, J.; Liu, M.-C.; Yuan, J.-X. 1-(Carboxymethyl)Uracil. Acta Crystallogr., Sect. E: Struct. Rep. Online 2005, 61, o2665-o2667.

(40) Tada, M. Antineoplastic Agents. The Preparation of 5Fluorouracil-1-Acetic Acid Derivatives. Bull. Chem. Soc. Jpn. 1975, $48,3427-3428$.

(41) Strovel, J.; Sittampalam, S.; Coussens, N. P.; Hughes, M.; Inglese, J.; Kurtz, A.; Andalibi, A.; Patton, L.; Austin, C.; Baltezor, M.; et al. Early Drug Discovery and Development Guidelines: For Academic Researchers, Collaborators, and Start-Up Companies; Assay Guidance Manual [Internet]; Eli Lilly \& Company and the National Center for Advancing Traslational Sciences: Bethesda (MD), 2004. PMID: 22553881 .

(42) Acton, C.; Miller, R.; Maltby, J.; Fullerton, D. Analysis of Variance (ANOVA). SPSS for Social Scientists; Macmillan Education UK: London, 2009; Vol. 6, pp 183-198.

(43) Wang, Q.-W.; Liu, X.-Y.; Liu, L.; Feng, J.; Li, Y.-H.; Guo, Z.-J.; Mei, Q.-B. Synthesis and Evaluation of the 5-Fluorouracil-Pectin Conjugate Targeted at the Colon. Med. Chem. Res. 2007, 16, 370379. 